\title{
Traumatic Dural Venous Sinus Thrombosis in High-Risk Acute Blunt Head Trauma Patients
}

W. Akhtar

Aga Khan University

Follow this and additional works at: https://ecommons.aku.edu/pakistan_fhs_mc_radiol Part of the Radiology Commons

\section{Recommended Citation}

Akhtar, W. (2010). Traumatic Dural Venous Sinus Thrombosis in High-Risk Acute Blunt Head Trauma Patients. Radiology, 256(3), 1014-1015.

Available at: https://ecommons.aku.edu/pakistan_fhs_mc_radiol/74 
strategy was used in the second period. Analysis was based on the 7755 chests radiographs performed in the 424 adult patients in the routine group and 425 in the on-demand group, all of whom were mechanically ventilated for at least 2 days. While the on-demand strategy of prescription was associated with a mean decrease of $32 \%$ in the number of chest radiographs performed, there was no significant difference between the two groups of patients in any of the secondary outcome measures: number of radiographs with findings leading to diagnostic procedures or therapeutic interventions, days of mechanical ventilation, length of stay in the ICU, and mortality of patients during their stay in the ICU. The results of our study suggest that unselective daily routine chests radiographs can be safely abandoned in adult mechanically ventilated patients in ICUs. The findings of our large multicenter study highly reinforce the conclusion in the meta-analysis by Drs Oba and Zaza.

\section{References}

1. Oba Y, Zaza T. Abandoning daily routine chest radiography in the intensive care unit: metaanalysis. Radiology 2010;255(2):386-395.

2. Hejblum G, Ioos V, Vibert JF, et al. A webbased Delphi study on the indications of chest radiographs for patients in ICUs. Chest 2008; 133(5):1107-1112

3. Lessnau KD. From Delphi to knowledge and comfort: the devil is in the details. Chest 2008;133(5):1060-1062.

4. Siegel MD, Rubinowitz AN. Routine daily vs on-demand chest radiographs in intensive care. Lancet 2009;374(9702):1656-1658.

5. Clec'h C, Simon P, Hamdi A, et al. Are daily routine chest radiographs useful in critically ill, mechanically ventilated patients? a randomized study. Intensive Care Med 2008; 34(2):264-270.

6. Krivopal M, Shlobin OA, Schwartzstein RM. Utility of daily routine portable chest radiographs in mechanically ventilated patients in the medical ICU. Chest 2003;123(5): 1607-1614.

7. Hejblum G, Chalumeau-Lemoine L, Ioos V, et al. Comparison of routine and on-demand prescription of chest radiographs in mechanically ventilated adults: a multicentre, clusterrandomised, two-period crossover study. Lancet 2009;374(9702):1687-1693.

\section{Comment on Parameters of Low-Grade Glioma as Predictors}

\section{From}

Johan Pallud, MD,* Laurent Capelle, $\mathrm{MD},{ }^{\dagger}$ and Emmanuel Mandonnet, $\mathrm{MD}, \mathrm{PhD}^{*}$

Department of Neurosurgery,

Sainte-Anne Hospital, Paris, France* Department of Neurosurgery, PitiéSalpêtrière Hospital, Paris, France Department of Neurosurgery, Lariboisière Hospital, 2 rue Ambroise Paré, 75010 Paris, France e-mail: mandonnet@mac.com

\section{Editor:}

We enjoyed reading the article by Dr Brasil Caseiras and colleagues (1). The authors are to be congratulated for this rigorous study, which shows how the "assessment of short-term tumor growth with magnetic resonance imaging can help stratify the risk of malignant transformation in patients with low-grade glioma and might influence the timing of aggressive therapy." In the study, they propose a threshold value of a $6.21-\mathrm{cm}^{3}$ volumetric increase in 6 months.

However, we wonder why the authors did not report the growth rates in terms of mean diameter as well (2). We will explain why this might be useful. Let us consider what might comprise a $6.21-\mathrm{cm}^{3}$ volume increase over 6 months, when converted to annual diameter growth rates, for tumors of different initial sizes. For a small $\left(4-\mathrm{cm}^{3}\right)$ tumor, this yields the rate of $14.6 \mathrm{~mm} / \mathrm{y}-\mathrm{a}$ value highly suggestive of a high-grade gliomawhereas, for an $80-\mathrm{cm}^{3}$ tumor, we obtain a typical grade II growth rate of $2.7 \mathrm{~mm} / \mathrm{y}$. In other words, this volumeincrease threshold may represent both large tumors with low growth rates and small tumors with high growth rates. Our guess is that this parameter, which was found to have prognostic value, is a combination of two independent prognostic factors: initial volume (eg, "age" of the tumor) and tumor growth rate (eg, tumor aggressivity). To help readers get a better idea of the contribution of each of these factors, we strongly encourage the authors to analyze their results in terms of mean diameter as well. We look forward to knowing whether the $8-\mathrm{mm} / \mathrm{y}$ threshold value of aggressivity found in our series (3) is supported by this otherwise methodologically robust study.

Acknowledgment: E.M. is supported by the Fondation de France.

\section{References}

1. Brasil Caseiras G, Ciccarelli O, Altmann DR, et al. Low-grade gliomas: six-month tumor growth predicts patient outcome better than admission tumor volume, relative cerebral blood volume, and apparent diffusion coefficient. Radiology 2009;253(2):505-512.

2. Mandonnet E, Pallud J, Clatz O, et al. Com putational modeling of the WHO grade II glioma dynamics: principles and applications to management paradigm. Neurosurg Rev 2008; $31(3): 263-269$.

3. Pallud J, Mandonnet E, Duffau H, et al. Prognostic value of initial magnetic resonance imaging growth rates for World Health Organization grade II gliomas. Ann Neurol 2006; 60(3):380-383.

Traumatic Dural Venous Sinus Thrombosis in High-Risk Acute Blunt Head Trauma Patients

From

Waseem Akhtar, FCPS

Department of Radiology, Aga Khan University, Stadium Rd, Karachi,

Sind 75800, Pakistan

e-mail: waseem.mirza@aku.edu

\section{Editor:}

I read with interest the article by Dr Delgado Almandoz and colleagues that appeared in the May 2010 issue of Radiology (1). I appreciate their effort to contribute to the establishment of evidence-based guidelines for diagnosis and treatment of this important clinical entity. The title and main objective (to calculate prevalence of traumatic dural venous sinus thrombosis [DVST] in high-risk trauma patients) are misleading and inappropriate. The authors have actually calculated the proportion, without confidence intervals, of DVST in a selected sample of patients. Therefore, these are not true estimates of disease, 
and inferences should be drawn with caution. Substantial selection and observer bias, inadequate sample size, lack of repeatable disease definition, and questionable validity of the outcome assessment tool are the major factors hampering the study's clinical implications. A good-quality survey is required to estimate the burden of DVST in high-risk patients with acute blunt head trauma, along with associated factors to propose a particular imaging algorithm.

\section{Reference}

1. Delgado Almandoz JE, Kelly HR, Schaefer PW, Lev MH, Gonzalez RG, Romero JM. Prevalence of traumatic dural venous sinus thrombosis in high-risk acute blunt head trauma patients evaluated with multidetector CT venography. Radiology 2010;255(2):570-577.

\section{Response}

From

Josser E. Delgado Almandoz, MD, ** Hillary R. Kelly, MD, * Pamela W. Schaefer, MD,* Michael H. Lev, MD,* R. Gilberto Gonzalez, MD, PhD, * and Javier M. Romero, MD* Division of Neuroradiology, Department of Radiology, Massachusetts General Hospital, Boston, Mass*

Division of Neuroradiology, Mallinckrodt Institute of Radiology, Washington University School of Medicine, 510 S Kingshighway Blvd, Campus Box 8131, St Louis, MO $63110^{+}$

e-mail:delgadoj@mir.wustl.edu

We have read Dr Akhtar's letter regarding our recent Radiology article (1) and hereby provide our reply. At our institution, all blunt head trauma patients with skull fractures in the vicinity of a dural venous sinus are screened with computed tomographic venography to exclude traumatic DVST. Hence, we believe that the reported frequency of traumatic DVST in our study does reflect the prevalence of this disease entity in our specific high-risk patient population. Nevertheless, we recognize that our findings may not be generalizable to other patient populations. The majority of Dr Akhtar's comments regarding the lim- itation of our retrospective study have already been acknowledged in the article. However, we would like to note that (a) to date, our study constitutes the largest published patient series on this topic; (b) we used a precise imaging definition for both nonocclusive and occlusive DVST; and (c) screening all of these patients with the reference standard of conventional angiography would be imprudent.

\section{References}

1. Delgado Almandoz JE, Kelly HR, Schaefer PW, Lev MH, Gonzalez RG, Romero JM. Prevalence of traumatic dural venous sinus thrombosis in high-risk acute blunt head trauma patients evaluated with multidetector CT venography. Radiology 2010;255(2): $570-577$.

\section{Aortopathy in Bicuspid Aortic Valve Disease: Is It Really Congenital?}

From

Evaldas Girdauskas, MD,* Michael A. Borger, MD, PhD, ${ }^{\dagger}$ and Thomas Kuntze, MD*

Department of Cardiac Surgery, Zentralklinik Bad Berka, Thüringen 99437, Germany* e-mail: evagird@centras.lt

Department of Cardiac Surgery, Heart Center Leipzig, Leipzig, Germany ${ }^{\dagger}$

\section{Editor:}

Dr Hope and colleagues have to be congratulated on their important contribution (1) to the field of bicuspid aortic valve (BAV) disease, which appeared in the April 2010 issue of Radiology. There is an ongoing debate regarding the origin of BAV aortopathy. The strong argument in mainstream genetic theory has been the high prevalence of proximal aortic dilation in patients with a BAV, which is out of proportion to the coexistent valvular lesions.

The most important message of this manuscript is the evidence of abnormal flow patterns in the ascending aorta in patients with a BAV and without substantial valvular lesions. The authors used sophisticated magnetic resonance (MR) imaging to demonstrate abnormal in vivo hemodynamics as a consequence of the bicuspid nature of aortic valve. This supports the extensive experimental work done by Robicsek et al (2). Moreover, Dr Hope and colleagues found two different flow patterns, which are specific to the two most common cusp fusion types in patients with a BAV. This suggests a hemodynamic origin of the recently identified BAV phenotypes (3-5). Fusion of the right and left coronary cusps generates a right-anterior flow jet that might result in larger aortic root dimensions $(3,4)$ and asymmetric dilatation of the ascending aorta (6). A leftposterior flow jet, which is seen in patients with right-noncoronary cusp fusion, might explain the increased aortic arch dimensions in this subgroup of patients with a BAV $(3,6)$. This heterogeneity of concomitant aortic pathologic findings in BAV disease would be difficult to explain with a pure genetic theory.

The article by Dr Hope and colleagues gives rise to some intriguing questions: Is there any explanation for the normal flow pattern in five patients with a BAV? Are there any other distinctive characteristic in these five patients with a BAV, apart from milder aortic valve disease? Did the authors look for the differences in aortic dilatation pattern between the two cusp fusion types (ie, right-left vs right-noncoronary)? Finally, could MR imaging be of value in demonstrating the distribution of aortic wall stress, which might be expected to differ between the two cusp fusion types?

In summary, this article provides valuable data in favor of a hemodynamic origin of BAV aortopathy. As the debate is ongoing, future research should focus on the detailed analysis of BAV phenotypes.

\section{References}

1. Hope MD, Hope TA, Meadows AK, et al. Bicuspid aortic valve: four-dimensional MR evaluation of ascending aortic systolic flow patterns. Radiology 2010;255(1):53-61.

2. Robicsek F, Thubrikar MJ, Cook JW, Fowler B. The congenitally bicuspid aortic valve: how does it function? why does it fail? Ann Thorac Surg 2004;77(1):177-185. 